\title{
Comparing Ground Motion Intensity, Root Mean Square of Acceleration and Time Duration from Four Definitions of Strong Motion
}

\author{
Heriberto Echezuría*
}

Universidad Catolica Andres Bello, Postgrado Ingenieria Estructural, Montalban, Caracas, Distrito Capital, Venezuela

\begin{abstract}
Variation of strong motion intensity, root mean square of ground acceleration and time-duration in seconds obtained from 83 accelerograms of 18 earthquakes with magnitudes between 5 to 7.7 were investigated considering four definitions of strong section of accelerograms given by Vanmarcke-Lai; Bolt, Trifunac-Brady and McCaan-Shah. Strong motion intensities were calculated for all definitions of strong duration. Even though, durations in seconds and root mean square of ground acceleration values resulted quite different among the four definitions of strong sections, both durations in seconds and root mean square of acceleration squared values tend to compensate each other to yield the same strong motion intensity for each definition used. Q-ratio as defined by Vanmarcke-Lai (Peak Ground Acceleration divided by root mean square of acceleration) was found not constant but instead it varied significantly for all strong motion definitions. Similarly, ratio of strong motion intensity over peak ground acceleration squared as defined by Vanmarcke-Lai holds linear for time durations less than 20-30 seconds for all definitions, afterwards it shows large dispersion. Finally, Vanmarcke-Lai time duration in seconds appears to increase from near field distance up to a certain medium distance after which it starts to decrease.
\end{abstract}

Keywords: Arias intensity, attenuation of seismic parameters, earthquake duration, earthquake energy, root mean square of acceleration, strong ground motion intensity.

\section{INTRODUCTION}

The root mean square of any variable which changes with time or distance, such as an acceleration time history or a cone resistance record with depth, has many applications in the statistical treatment of such variable when it is conceived as a random process. In the particular case of the acceleration time histories, the root mean square of the ground acceleration $\left(a_{r m s}\right)$ has been used by several authors [1-3] to define the strong section of the accelerogram.

Both, motion intensity and root mean square of acceleration can be used in the formulation of solutions for structure reliability problems. Arias intensity provides the measurement of the energy being applied to the structure and the root mean square of the acceleration provides an approximation to the standard deviation for stationary random processes, which include the usual treatment of earthquakes.

Then, it is interesting to investigate the variation of the root mean square of the ground acceleration considering the magnitude and some other seismic parameters taking into account the definition of duration used to establish the strong section of the acceleration time history. To achieve this, in this sttudy four definitions of durations: Vanmarcke-Lai (VL) [1]; Trifunac-Brady (TB) [2], Mc Caan-Shah (McS) [3] and Bolt (B) [4] were used to define the strong section of selected accelograms.

*Address correspondence to this author at the Universidad Catolica Andres Bello, Postgrado Ingenieria Estructural, Montalban, Caracas, Distrito Capital, Venezuela; Tel: 0058+4165396272; E-mails: hechezuria51@gmail.com, and heriberto.echezuria@yvsite.com
Three of those definitions VL, TB and McS use the root mean square of the ground acceleration in different ways and the other definition, B, uses an acceleration limit or bracketed value instead. The analysis was conducted in the following order; first, four durations were estimated for each included accelerogram by means of the different definitions mentioned above and duration in seconds, $\mathrm{D}(\mathrm{s})$, were established. Then; calculations were made for each accelerogram of other variables related to its strong section such as the resulting root mean square of the ground acceleration, $a_{r m s}$, and the intensity of the strong motion (Ism). This intensity will be defined later in the article. Finally, comparisons were made among those variables considering the definitions of duration, earthquake magnitude, and earthquake source to site-of-accelerogram recording distance.

The variation with distance of the duration in seconds, $\mathrm{D}(\mathrm{s})$, of the strong section of the accelerogram was investigated by comparing the results of expected mean values of the motion intensity obtained from crude regressions for each magnitude range studied with mean predictions of $a_{r m s}^{2}$ obtained from formal multiple nonlinear regressions done by [5].

\section{MATERIALS AND METHODOLOGY}

A data base composed of 83 acceleration records from 18 earthquakes set up by [5] was used for this study. It included the values of the seismic variables investigated, i.e. $a_{r m s}$, time duration in seconds, $\mathrm{D}(\mathrm{s})$ obtained by [5] using the four definitions of duration already mentioned, VL, TB, McS and 
B. Subsequently, the strong motion intensities were calculated for each earthquake using those two parameters as indicated in the next section of this article. The main objective was to discuss the differences or similarities among the seismic variables given that in the original work by [5] emphasis was done in the use of $a_{r m s}$ attenuation to evaluate the probabilistic liquefaction potential for Downtown San Francisco [6]. Thus, no particular discussion among those variables was done at that time.

For completeness of this article; first, the definition and a brief summary of the ground motion intensity and the four definitions of duration of the strong section of accelerograms are presented in the next section and then comparisons and correlations among values of the seismic variables are included and discussed in the other sections.

\subsection{Definition of Ground Motion Intensity and Brief De- scription of the Four Definitions of Strong Sections of Earthquake Duration used in the Study}

Arias [7] proposed a method to evaluate the energy dissipated during strong ground motion given by:

$$
\text { Ia }=\int_{0}^{\infty} E(\omega) d \omega
$$

where, $I a$, is the Arias intensity, and, E $\omega$, is the energy dissipated by an oscillator with natural frequency, $\omega$. It can also be shown that, when applied to an acceleration time history along with the power spectral concept the expression above can become:

Io $=a_{r m s}^{2} T d$

where, Io is the intensity of the motion, $a_{r m s}$ is the root mean square of the acceleration time record, and $\mathrm{Td}$ is the total duration of the record in seconds. The expression above indicates that the mean square of the ground acceleration can be taken as an average constant intensity acting during the total duration $\mathrm{Td}$ of the motion.

Vanmarcke and Lai (VL) as well as Trifunac and Brady (TB) used Arias intensity (Ia) in their definitions of duration. Trifunac and Brady defined the beginning of the strong motion section of the accelerogram as the time at which $5 \%$ of the $I a$ is reached and the end as the time which yields $95 \%$ of the Ia. Justification for this is that most earthquakes have low amplitude intervals early and late in the record.

Vanmarcke and Lai defined the duration based on the assumption that the $I a$ is uniformly distributed at a constant average power given by $a_{r m s}^{2}$ over the strong ground motion interval, Tsm. Further, those investigators assumed that the time history of acceleration is a Gaussian process and defined the relationship between peak ground acceleration PGA and $a_{r m s}$, as Q=PGA/ $a_{r m s}$. In addition, VL took arbitrarily the probability of exceeding at least once the ratio, $\mathrm{Q}$, during the time interval, $T s m$, as $1-e^{-1}$. Under these conditions the solution for $T s m$ can be obtained in terms of $I a$, Tsm, PGA and To, as follows:

$$
\begin{aligned}
& \text { Tsm }=Q^{2}\left(\operatorname{Ia} / P G A^{2}\right)=[2 \ln (2 \text { Tsm } / \text { To })]\left[I a / P G A^{2}\right] \text { For } \\
& \text { Tsm } \geq 1.36 \text { To }
\end{aligned}
$$

And

$T s m=Q^{2}\left(I a / P G A^{2}\right)=2 I a / P G A^{2}$ For $T s m<1.36$ To

where, Tsm is the duration of the strong motion and To, is the average period of the record. However, considering the arbitrariness of the selection of the probability of exceeding the, Q- ratio, during the time, Tsm, as well as the fact that they have found the ratio of $1 a / P G A^{2}$ to be close to linear, VL proposed a simplified version of the solution using a constant value for the ratio, Q-ratio $=2.74$. This simplified version was used in this study. The center of the duration corresponds to the location of the PGA and half of it is then taken towards de upper portion and the other half towards the lower portion.

McCaan and Shah defined the strong section of the accelerogram as the interval which exhibits a constant $a_{r m s}$ level. The beginning of the strong motion is obtained by forming the cumulative root mean square of the ground acceleration function of the reversed accelerogram and selecting the time at which the root mean square of the ground acceleration begins a steady decline. This time defines the beginning of the strong section and is denoted as, $T_{1}$. The end of the strong section is obtained by applying the same method to the original accelerogram starting at, $T_{1}$.

Bolt used a threshold value concept in order to define the strong part of the accelerogram. Once a threshold value of the acceleration is defined according to the phenomenon under study, the strong part is the enclosed portion between the first and last time the threshold is exceeded along the acceleration record. In this study a value of the acceleration of $0.05 \mathrm{~g}$ was used. Note that, $\mathrm{g}$, is the acceleration of gravity in centimeters per squared seconds.

In this work the intensity of the strong motion was defined in an analogous way to that given in eq. 3 as follows:

$I s m=a_{r m s}^{2} T s m \ldots$

where, Ism, is the intensity of the strong motion, $a_{r m s}$ is the root mean square of the accelerations contained in the strong section of the accelerogram corresponding to the strong section duration and, $T_{s m}$ is the duration in seconds of the strong motion definition in use.

\subsection{Composition of the Data Base used in the Study and Purpose of this Study}

The data based used in this study is the same used by the author [5] to develop attenuation relationships for $a_{r m s}$ values obtained with the four definitions already mentioned. The data based included records obtained in the near field, that is, less than $10 \mathrm{~km}$ of the fault. The distance definition, R, used in the study corresponds to the closest distance to the surface projection of fault rupture area. The $a_{r m s}$ were calculated using the four definitions of duration mentioned above, for a total of 83 accelerograms from 18 earthquakes with moment magnitudes between 5 and 7.7, as depicted in Table A-1 of Appendix 1.

The information generated with the data included in this study was used for evaluating the probability of liquefaction for San Francisco [6]. At that time, the investigation focused 

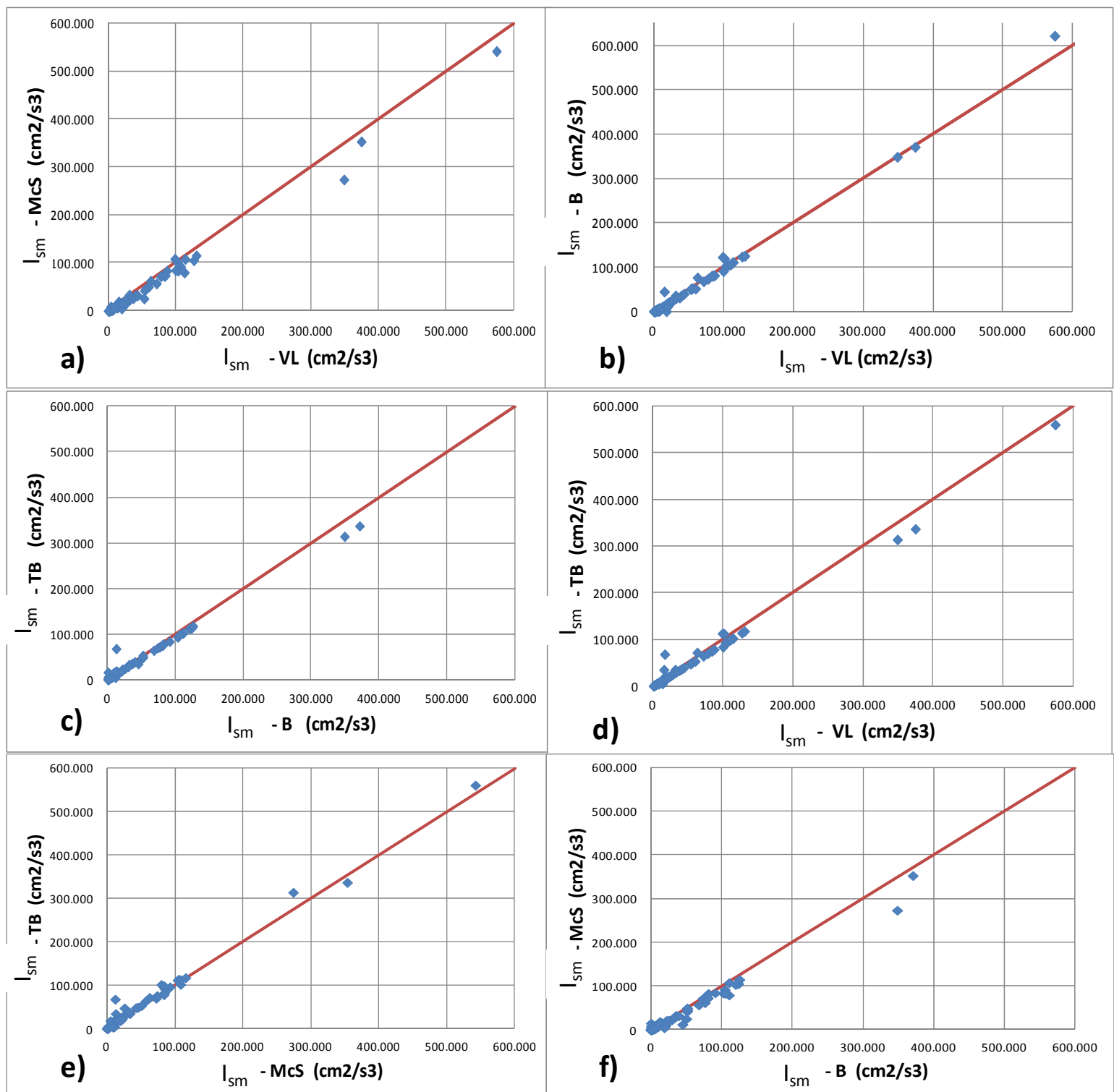

Fig. (1). Comparisons of strong motion intensities obtained with the four different definitions of duration for the accelerograms in the data base, a) $I s m-\mathrm{McS}$ vs $I s m$-VL, b) $I s m$-B vs $I s m$-VL, c) $I s m$-TB vs $I s m-\mathrm{B}$, d) $I s m$-TB vs $I s m$-VL, e) $I s m$-TB vs $I s m-\mathrm{McS}$, f) $I s m$-McS vs $I s m$-B.

on the attenuation of the $a_{r m s}$ and its applicability to determine the number of zero crossings in order to evaluate probabilistic liquefaction potential [6]. However, no attempt was done to discuss the seismic parameters themselves in the original study. Thus, as there have been very few articles related to discussions on the comparison of such seismic parameters from that time, the author took back the data generated to look into the details regarding earthquake duration which is the main objective of this article. All the variables used in this study are included in Table A-1 of Appendix $\mathbf{1}$.

\section{RESULTS}

Results are presented in the following order; first in section 3.1 values of strong motion intensity, Ism, are compared among them for the four definitions of duration. Then, comparisons among $a_{r m s}$ values obtained with the four definitions are also included. Similarly, comparisons were done for the $\mathrm{D}(\mathrm{s})$ values obtained with the four definitions. Section 3.2 includes plots showing the variation of the ratio $\mathrm{Ism} / \mathrm{a}_{\mathrm{rms}}^{2}$ with $\mathrm{D}(\mathrm{s})$; followed by the statistical analysis of Q-ratio $\left(\mathrm{PGA} / a_{r m s}\right)$ of strong section of accelerograms in the data base. Finally, In section 3.3 variations of $\mathrm{D}(\mathrm{s})$ with distance $\mathrm{R}$ in $(\mathrm{km})$ are explored for three magnitude ranges. As previously indicated, in this study $\mathrm{R}$ is the closest distance to the surface projection of fault rupture area.

3.1. Comparison Among Strong Motion Intensities, Ism, Durations in Seconds D(s) and Root Mean Square of Acceleration $a_{r m s}$, for the Four Definitions of Duration

The calculated strong ground motion intensity $\left(I_{s m}\right)$ using the four definitions of duration on the accelerograms in the data base are compared among each other as illustrated in Fig. (1). Note that despite de definition of duration they appear to be very close to each other. A detailed look at each figure indicates that there exist some variations for particular 


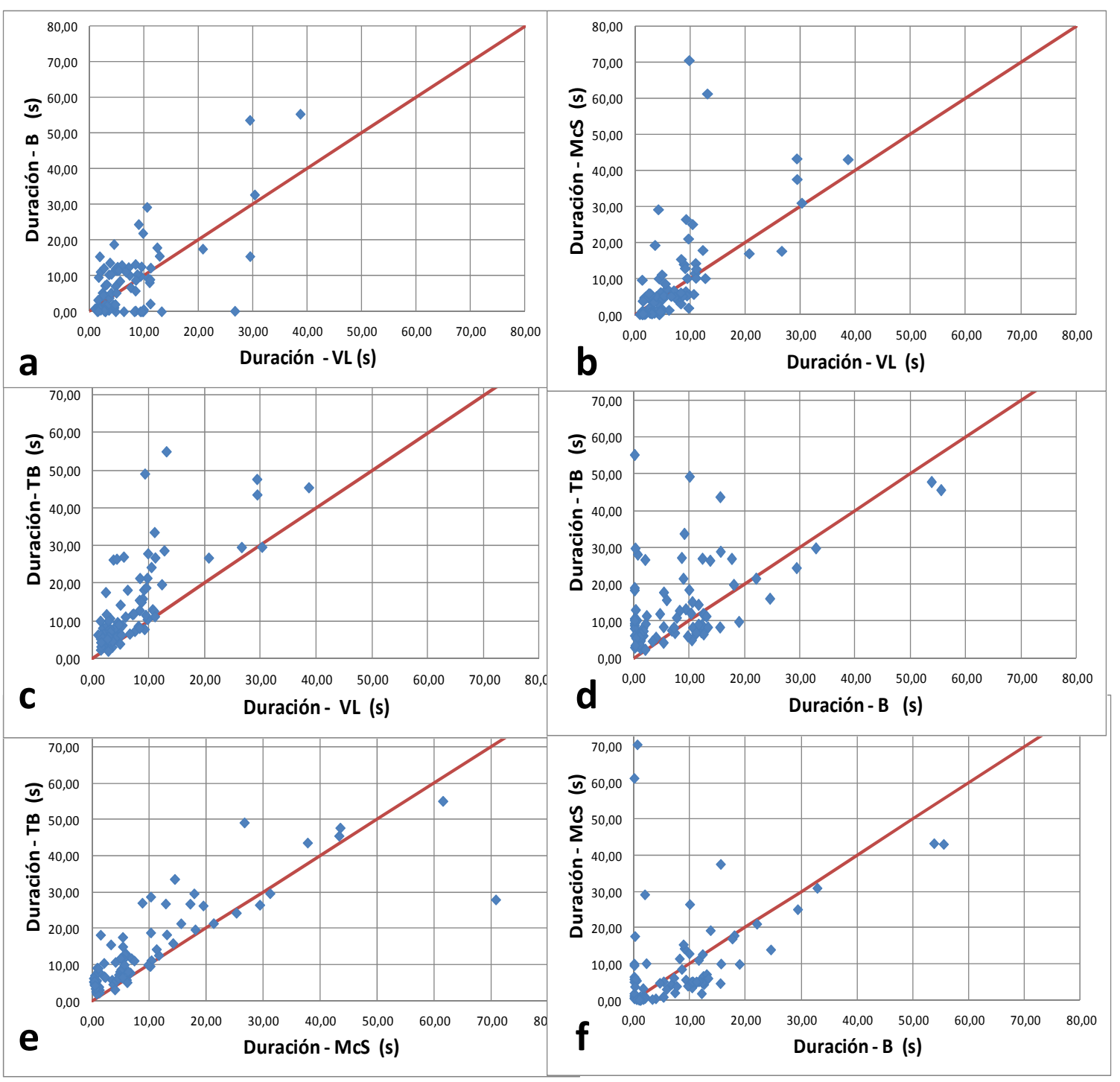

Fig. (2). Comparison of time durations in seconds for the strong part of the accelerograms obtained with the four different definitions of duration, a) D(s)-B vs D(s)-VL, b) D(s)-McS vs D(s)-VL, c) D(s)-TB vs D(s)-VL, d) D(s)-TB vs D(s)-B, e) D(s)-TB vs D(s)-McS, f) D(s)-McS vs $\mathrm{D}(\mathrm{s})-\mathrm{B}$.

sectors of the plots; however, it could be overlooked given the closeness of the results.

Durations in seconds and $a_{r m s}$ values for the strong section of the accelerograms used in the study are compared in Figs. ( 2 and 3 ) for the four definitions of duration. Note that they have significant scatter and that whenever the duration tends to decrease for a particular definition when compared to another one, then the $a_{r m s}$ tends to increase.

3.2. Variation of $I s m / a_{r m s}^{2}$ Ratio with $\mathbf{D}(\mathbf{s})$ and Statistical Analysis of Q-ratio $\left(P G A / a_{r m s}\right)$ for the Strong Section of Accelerograms

According to VL definition of duration, the ratio between strong motion intensity (Ism) and $P G A^{2}$ for the strong part of the accelerograms should be linearly proportional to duration in seconds, D(s). Plots of the ratio of Ism over $P G A^{2}$ vs $\mathrm{D}(\mathrm{s})$ are shown in Fig. (4) for the four definitions of duration. It is observed that linearity between these two variables holds for a very narrow range of distances.
Plots of histograms for the Q-ratio $\left(P G A / a_{r m s}\right)$ defined by VL are shown in Fig. (5) for the four definitions of duration. According to VL this Q-ratio should be a constant and may be taken for practical purposes equal to 2.74 for the strong motion duration, $T s \mathrm{sm}$, of the accelerogram. Note that for the strong section of the accelerogram the values of this parameter are different from that reported by VL and depend upon the definition selected. Even though the VL is the only definition that explicitly uses this parameter, its calculation is included for the others definitions for comparison purposes regarding the strong section of the accelerograms.

\subsection{Variation of Durations in Seconds $D(s)$ for the Four Definitions of Duration with Distance, $R$}

Regarding the durations in seconds $\mathrm{D}(\mathrm{s})$ of the strong section of the accelerograms, Figs. (6-8) show its variation with distance for the four definitions used and ranges of magnitudes $5<\mathrm{M}<5.9 ; 6<\mathrm{M}<6.6$ and $7<\mathrm{M}<7.7$. 

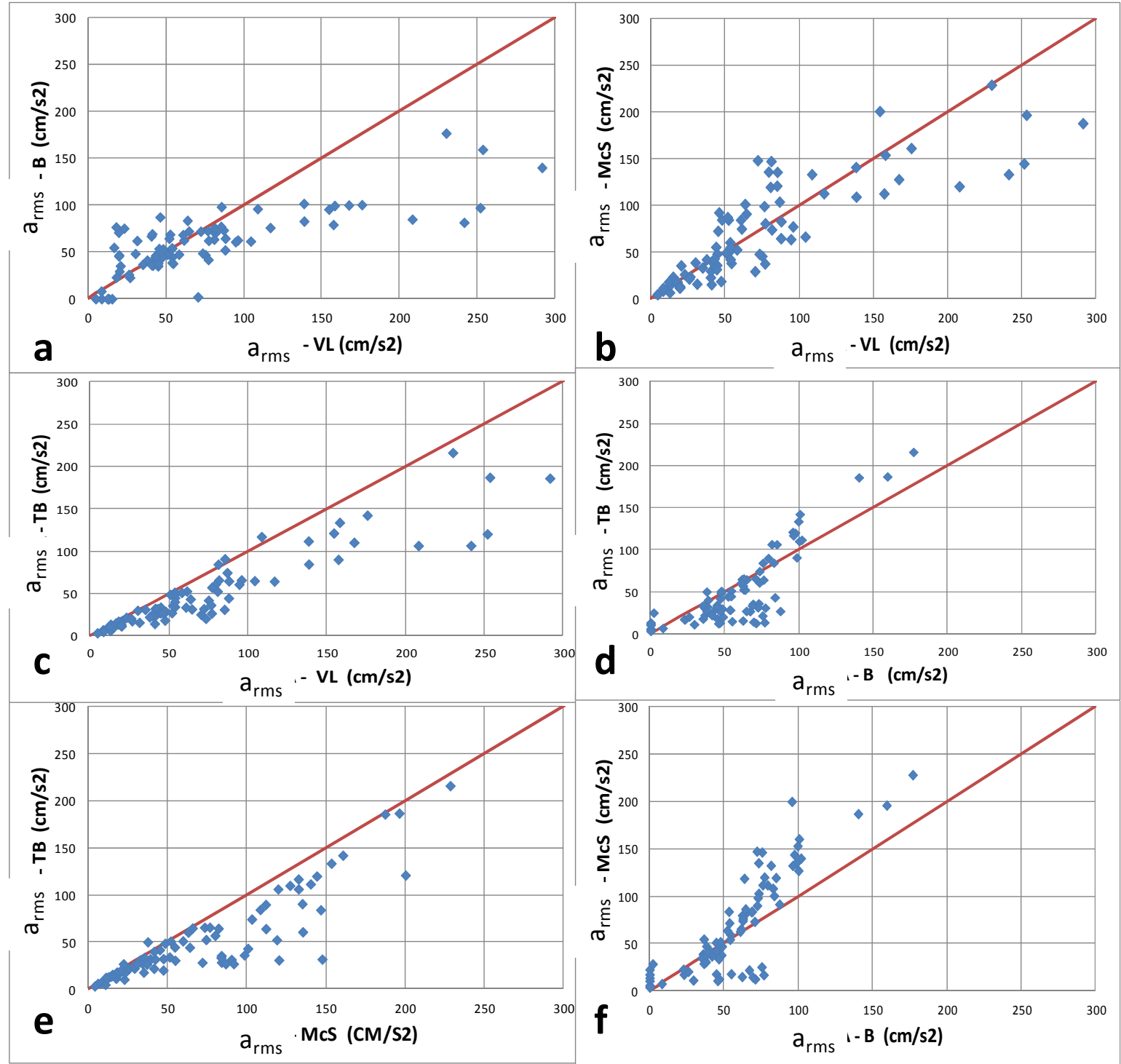

Fig. (3). Comparison of the root mean square of the ground acceleration values obtained with the four different definitions of duration, a) $a_{r m s}$ -B vs $\left.a_{r m s}-\mathrm{VL}, \mathbf{b}\right) a_{r m s}-\mathrm{McS}$ vs $a_{r m s}-\mathrm{VL}$, c) $a_{r m s}-\mathrm{TB}$ vs $\left.a_{r m s}-\mathrm{VL}, \mathbf{d}\right) a_{r m s}-\mathrm{TB}$ vs $\left.a_{r m s}-\mathrm{B}, \mathbf{e}\right) a_{r m s}-\mathrm{TB}$ vs $a_{r m s}$ McS, f) $a_{r m s}-\mathrm{McS}$ vs $a_{r m s}-\mathrm{B}$.

\section{DISCUSSION OF RESULTS}

\subsection{Discussion on $a_{r m s}$ values and duration in seconds of strong section of accelerograms}

As seen in Fig. (1); the strong motion intensities obtained with the four definitions used are so close to each other that they could be considered as similar or equivalent for all practical purposes. This is a very interesting finding because the four definitions use different conceptual basis, even though only two of them (VL and TB) use explicitly the Arias intensity.

Definition by $\mathrm{McS}$ uses the decline in $a_{r m s}$ in a way which is not necessarily related to $I a$ and Bolt definition of duration does not consider the $a_{r m s}$ or Arias intensity at all. However, all of the definitions involve the location of the PGA and the nearby accelerations which might be associated to the main period of the acceleration record and in turn yield this interesting result.
Despite the finding previously described, durations in seconds and $a_{r m s}$ values are quite different for the four definitions as depicted Figs. (2 and 3). It means that even though the definitions yield almost a unique value of the energy for the strong section of the accelerogram, the duration in seconds as well as the $a_{r m s}$ related to such duration may vary significantly from one definition to the other. Note also that durations in seconds as well as $a_{r m s}$ have significant scatter and that whenever the duration tends to decrease for a particular definition then the $a_{r m s}$ tends to increase. See Figs. (2 and 3).

In addition, note also in Fig. (2c) that the TB durations in seconds are about double than those from VL. Similarly; $\mathrm{McS}$ durations in seconds seem to be in agreement with those from VL for low $a_{r m s}$ values, whereas for large $a_{r m s}$ values they show significant scatter. Moreover; TB durations tend to be larger than those from $\mathrm{McS}$. 

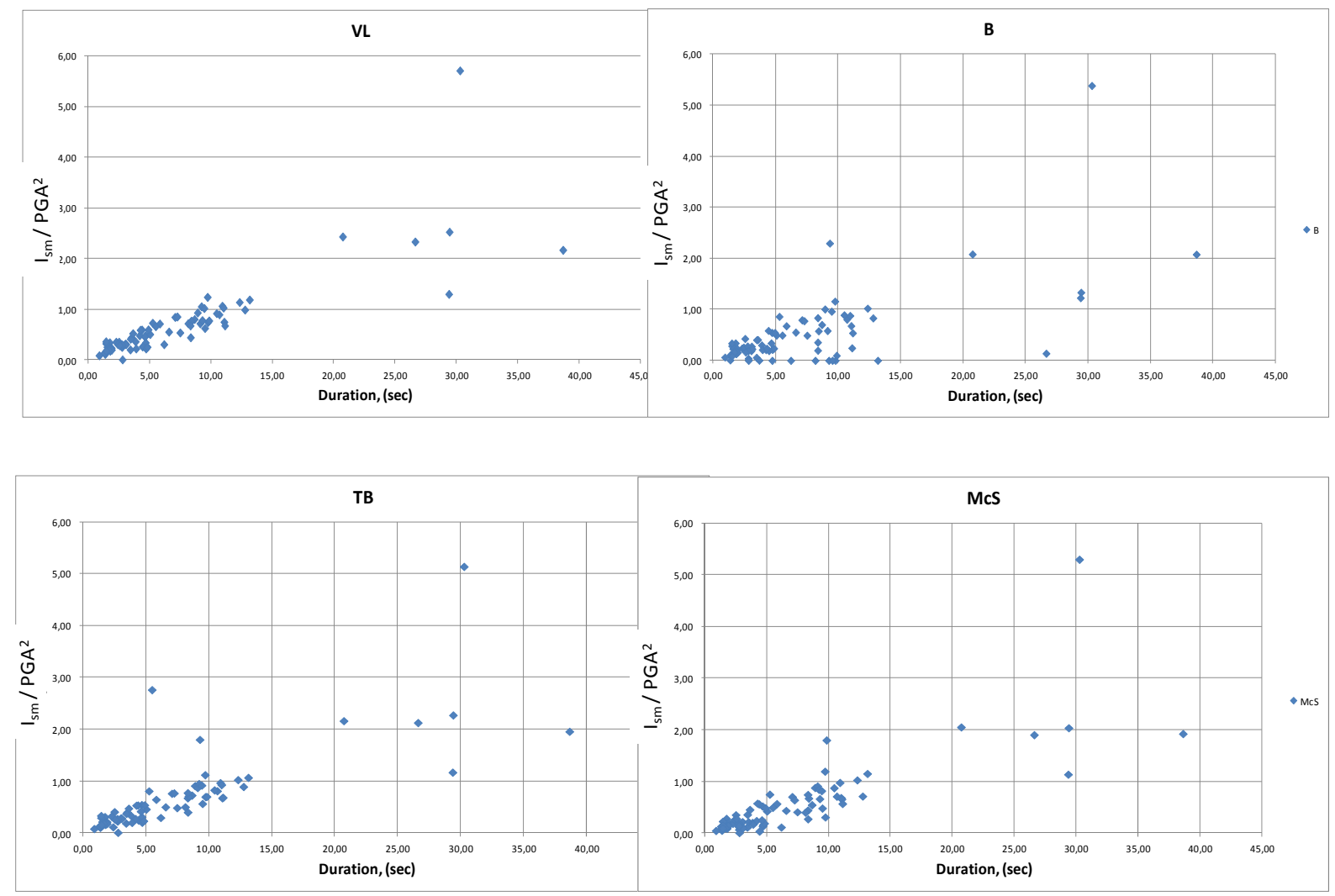

Fig. (4). Ratio between strong motion intensity (Ism) over PGA squared versus duration in seconds, D(s), for the strong part of the accelerograms obtained with the four definitions of duration identified in each figure.

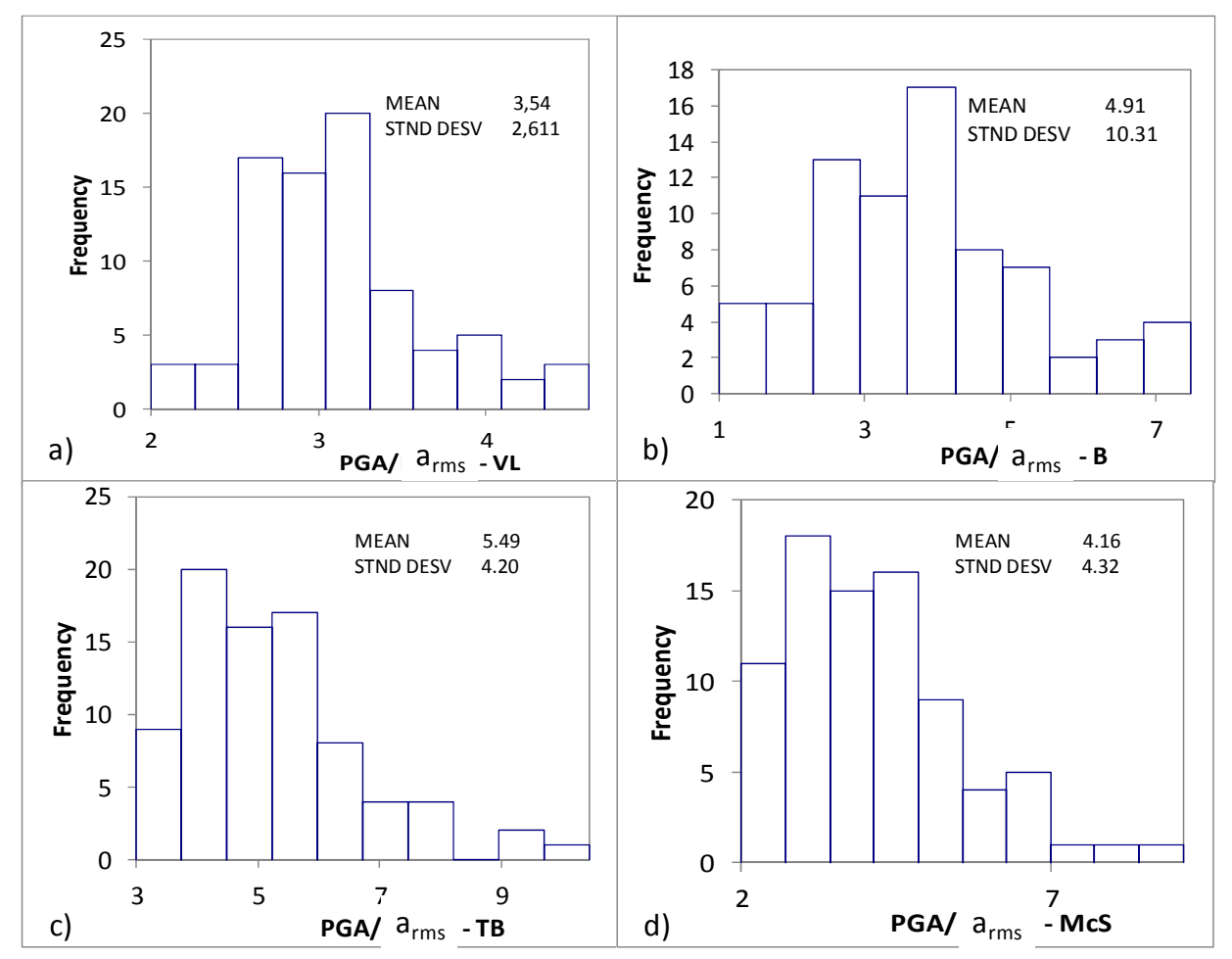

Fig. (5). Histograms of the Q-ratio between $P G A$ and $a_{r m s}$ for the strong part of the accelerograms obtained with the four different definitions of duration, a) VL, b) B, c) TB and d) McS. 


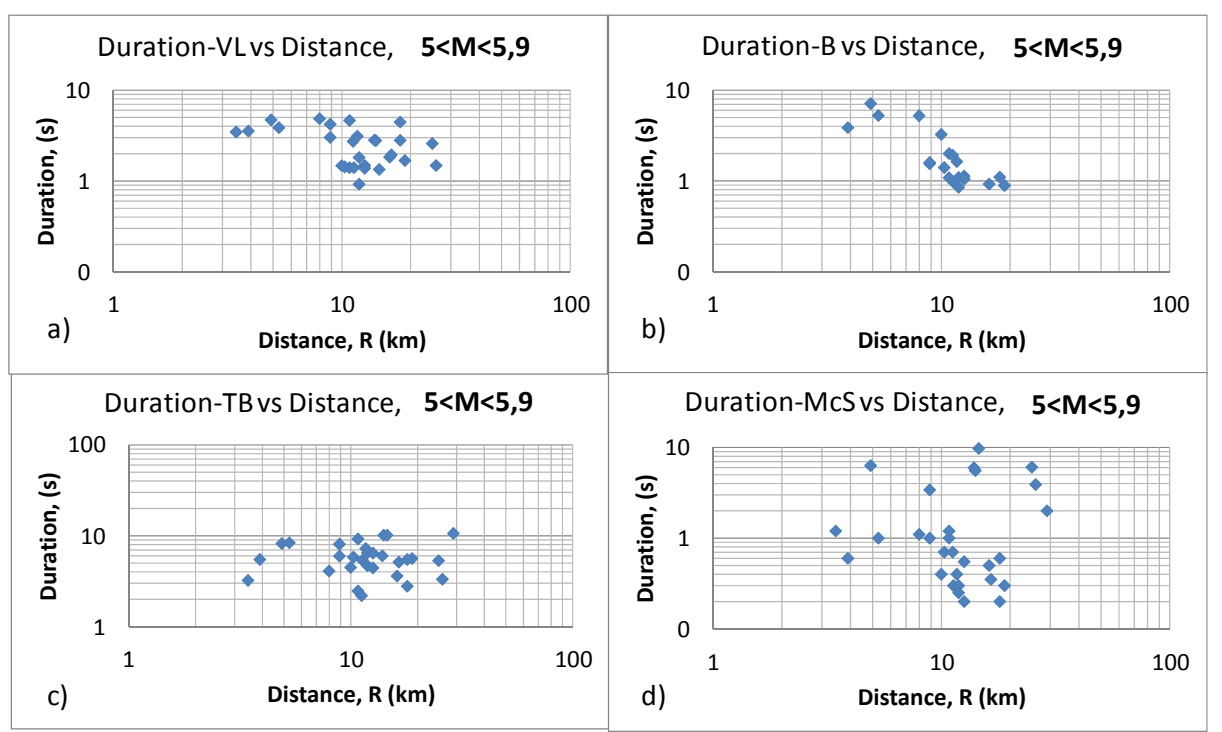

Fig. (6). Plot of duration in seconds with distance for magnitude range of $5<\mathrm{M}<5.9$ and the four definitions of duration, a) VL, b) $\mathrm{B}$, c) TB and d) $\mathrm{McS}$.

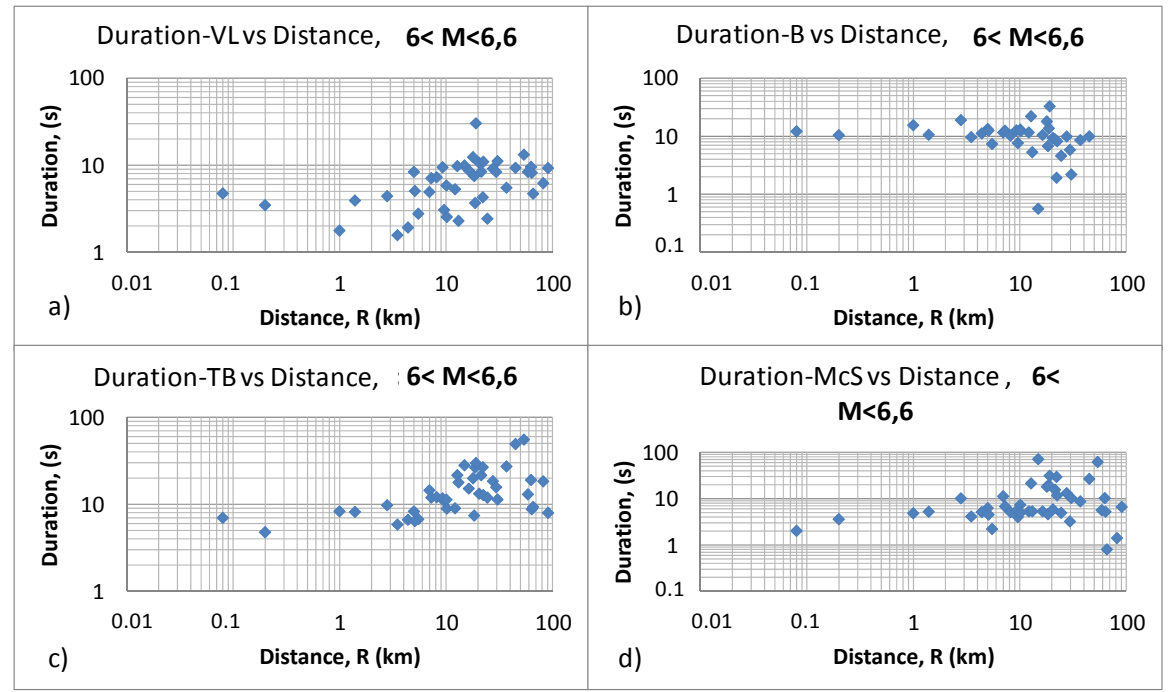

Fig. (7). Plot of duration with distance for magnitude range of $6<M<6.6$ and the four definitions of duration, a) VL, b) B, c) TB and d) McS.

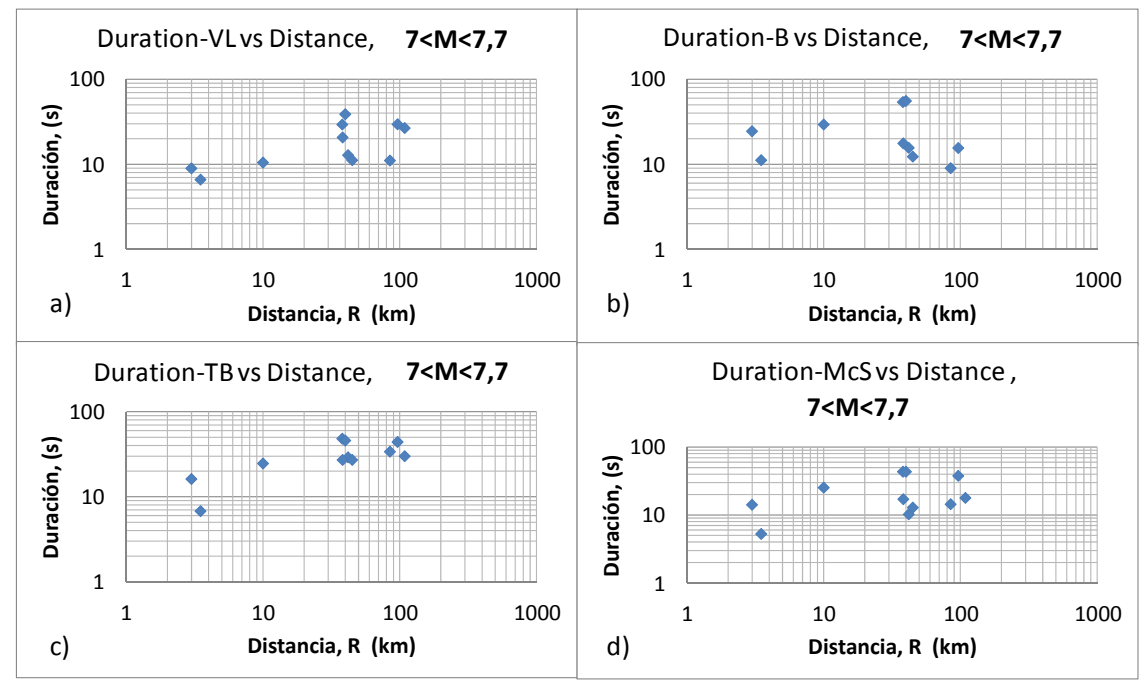

Fig. (8). Plot of duration with distance for magnitude range of $7<\mathrm{M}<7.7$ and the four definitions of duration, a) VL, b) $B$, c) TB and d) McS. 
A close look to eq. 2 and 5 indicates that there should be compensation between duration and $a_{r m s}$ for the strong section of the accelerogram in such a way that when one of those variables is reduced the other increases and compensates to yielding the same energy value.

The aforementioned aspects have an important implication related to what engineers mean when defining the strong section of an accelerogram. For instance, structural engineers are usually more concerned with the acceleration values which initiate damages to structures and continue its deterioration process throughout the ground movement. For geotechnical engineers it is important to identify accelerations which initiate the increase in pore water pressure for liquefaction and continue increasing it. In those cases the beginning of the strong section of an accelerogram might be more closely related to the absolute values of the acceleration and its root mean square value rather than with the energy itself. Nevertheless, energy has other applications related to power and number of equivalent cycles among others. These particular aspects require more research considering also the fact that all definitions explored in this article yield values of energy very close to each other.

The $a_{r m s}$ values from B appear to have the largest dispersion of all definitions, see Fig. (1). It may be due to the threshold value used $(0.05 \mathrm{~g})$. As discussed previously in section 2.1 of this article, this value was selected because it was taken as the one that initiates the increment of pore water pressure. However, if different criteria were used to select the initiating damage and the end damage, it may be possible to obtain better results with this definition of strong section of an accelerogram. Note that with this it is implied to use one value for the initiation and a different one for the end. This should be further investigated.

\subsection{Discussion on Q-Ratio and Duration in Seconds of Strong Section of Accelerograms}

Plots of Q-ratio vs $\mathrm{D}(\mathrm{s})$ as defined by VL are shown in Fig. (4) for the four definitions of duration. According to those authors it should be linear with duration in seconds, $\mathrm{D}(\mathrm{s})$. Note in Fig. (4) that linear proportionality indicated by VL holds well for values of durations lower than about 20 to 30 seconds for the four definitions. It can be also observed in Fig. (4) that above those values of $\mathrm{D}(\mathrm{s})$ there is a very large scatter for all definitions. Note also that, the VL definition shows a better correlation below 30 seconds than all other definitions of strong durations. The definition by, B, has the poorest correlation of all. All these aspects are also worth investigating.

Another interesting aspect is that, according to the definitions of VL, the Q-ratio between $P G A$ and $a_{r m s}$ should be a constant and may be taken for practical purposes equal to 2.74 for the strong motion duration, Tsm, of the accelerogram. This criterion was used when applying the VL method to the data base.

However; even though the VL definition uses a value of 2.74 to define the strong section of an accelerogram, the outcome shown in Fig. (5) for the resulting strong part of the accelerograms indicates that this ratio is not nearly constant and has a mean value equal to 3.54 , at least for the data base used herein. It can be also noted in Fig. (5) that the VL definition has the narrower range as well as the smaller standard deviation for this variable when obtained with the four definitions used. Nevertheless, it is not in agreement with the assumptions of VL, as mentioned above, and further research will help to better understand these facts.

Plots of the values of the Q-ratio showing the mean as well as the standard deviation are also included in Fig. (5), for the other definitions of duration, TB (5.49), B (4.91) and $\mathrm{McS}$ (4.16). It can be inferred that VL definition is more consistent in selecting shorter strong sections of the accelerogram around the PGA, even though the Q-ratio is somewhat larger than originally assumed. It is also in agreement with the fact that durations in seconds for the other definitions tend to be larger than those with the VL definition. This also implies that the VL definition may include larger values of the accelerations that may cause damage to structures and liquefaction as discussed above.

\subsection{Discussion on Variation of Duration in Seconds of Strong Section of Accelerograms with Distance}

Plots of duration in seconds $\mathrm{D}(\mathrm{s})$ with distance shown in Figs. (6-8) for three ranges of magnitudes indicate that all the definitions tend to yield low values of duration at short distances which increase as distance also increases up to a point at which it reduces from that distance on. However, some of the plots exhibit such a large dispersion which somewhat masks this fact.

In order to look into this in a different way, one can consider the fact that energy in terms of motion intensity, Ism, is estimated by the product of the $a_{r m s}$ squared times the duration in seconds, see eq. 2 and 5. Consequently, it is worth exploring the variation with distance of both, the $I s m$, and $a_{r m s}$ to try to infer the behavior of duration with distance. This is included in Figs. (9-11) for the three magnitude ranges previously mentioned.

It is noticed in Figs. (9-11) that for the three magnitude ranges the decay with distance of the motion intensity is faster than that for the root mean square of the ground acceleration. At this point the author has not done any formal mathematical treatment for the attenuation of the motion intensity, as was preformed for the root mean square of the ground acceleration in the previous work [5] with multiple non linear regressions on magnitude and distance.

The aforementioned approach was used due to the fact that there is not a formal mathematical model for the variation of Ism with distance and it was not the objective of this work. However, for the purpose of illustration only, one could approximate the crude mean prediction of the motion intensity from individual regressions with distance for each magnitude range and compare it to the square of the mean prediction of the $a_{r m s}$ with distance developed by [5]. This is done in Fig. (12), using a model with near field saturation for the $a_{r m s}$ [5] and a crude approximation of the mean for the $a_{r m s}$ for each magnitude range. Fig. (12) also includes the squared mean values of the $a_{r m s}$ from VL definition for the three ranges of magnitude used. 


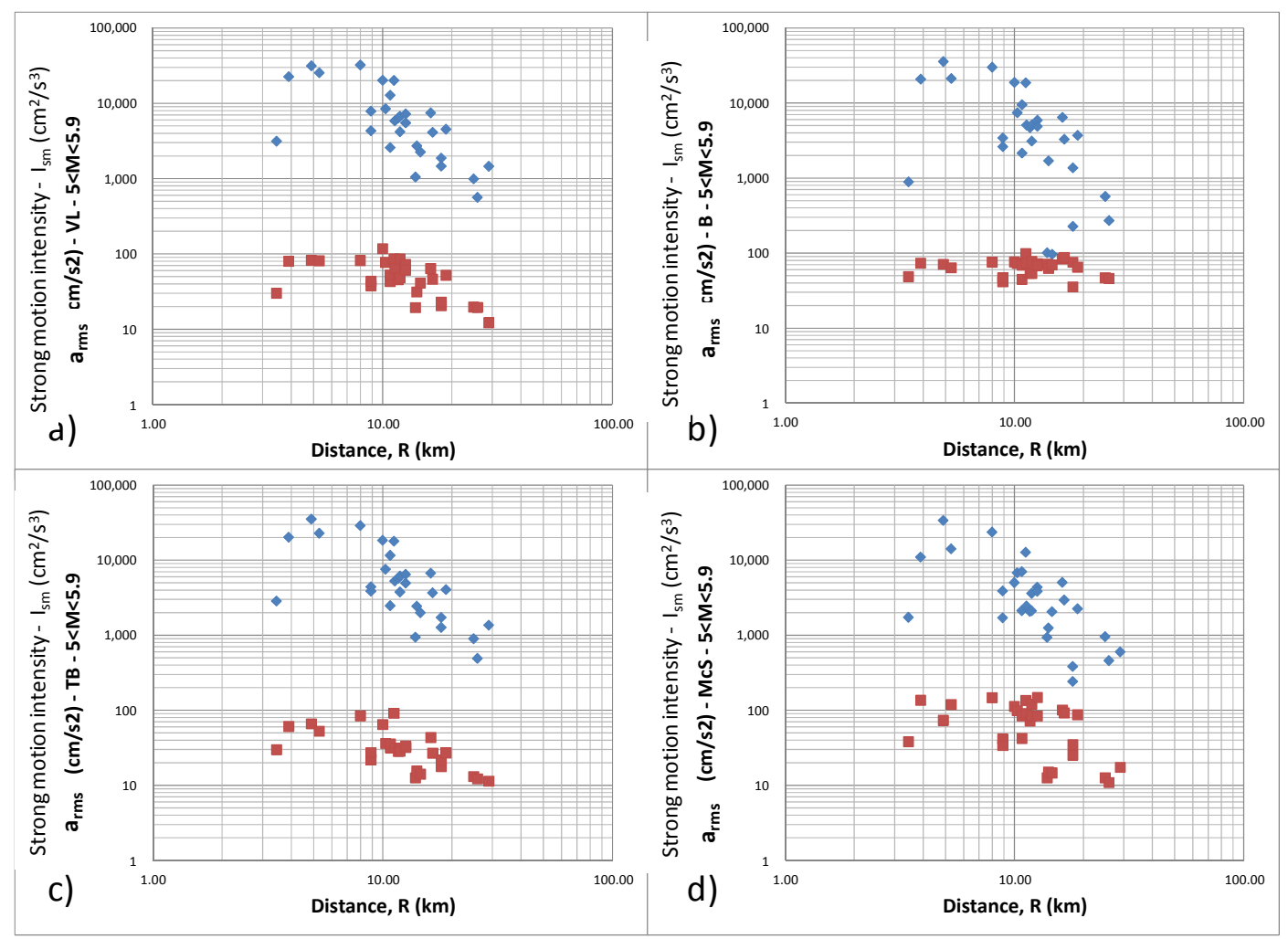

Fig. (9). Decay with distance of the motion intensity, Ism, obtained with the four definitions of duration, as identified in the axis, for $5<\mathrm{M}<5$.9. Include also the variation of $a_{r m s}$ with distance for the same magnitude range, a) $\left.\left.\mathrm{VL}, \mathbf{b}\right) \mathrm{B}, \mathbf{c}\right) \mathrm{TB}$ and d) $\mathrm{McS}$.

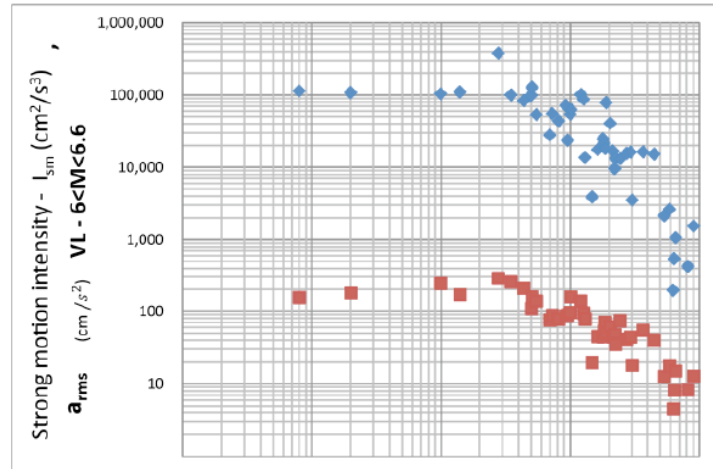

a)

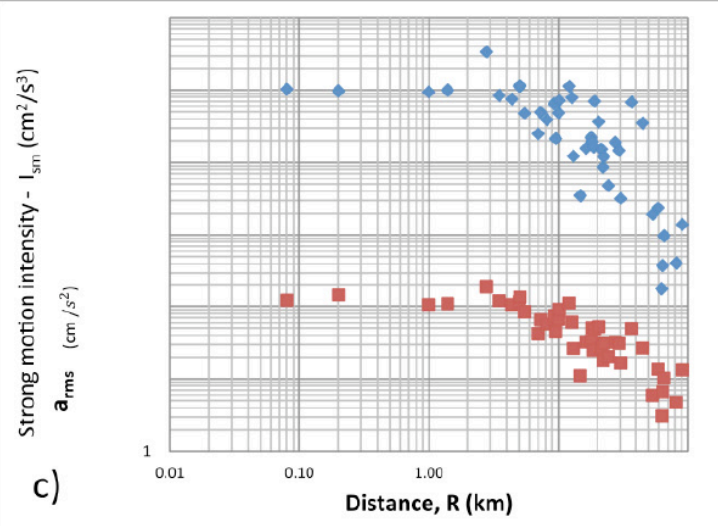

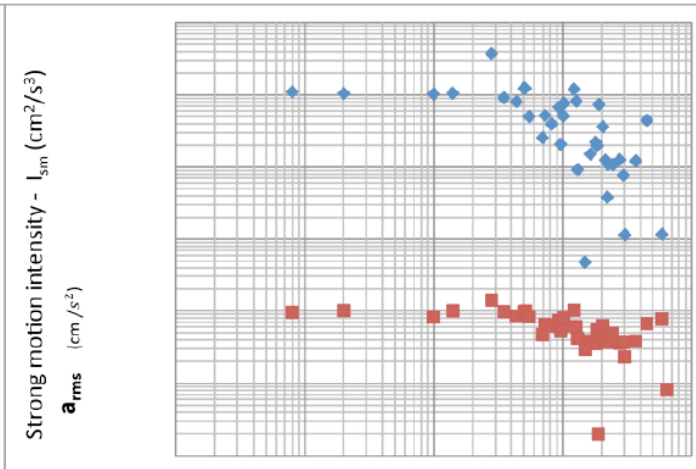

b)

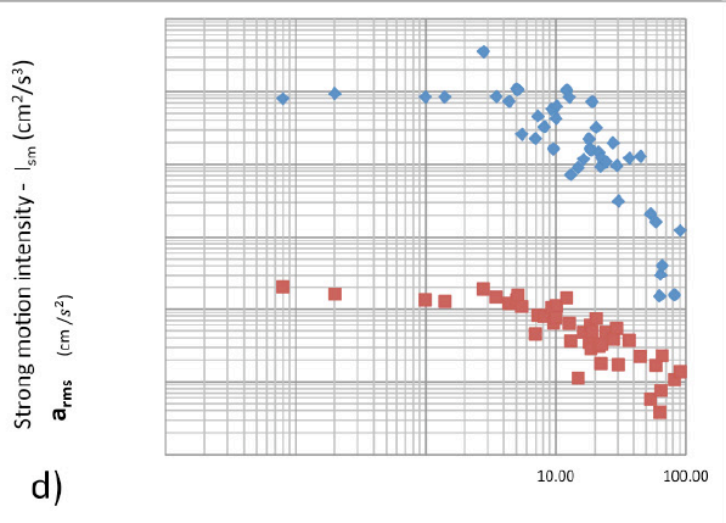

Fig. (10). Decay with distance of the motion intensity, Ism, obtained with the four definitions of duration for $6<\mathrm{M}<6.6$. Include also the variation of $a_{r m s}$ with distance for the same magnitude range, a) VL, b) B, c) TB and d) McS. 

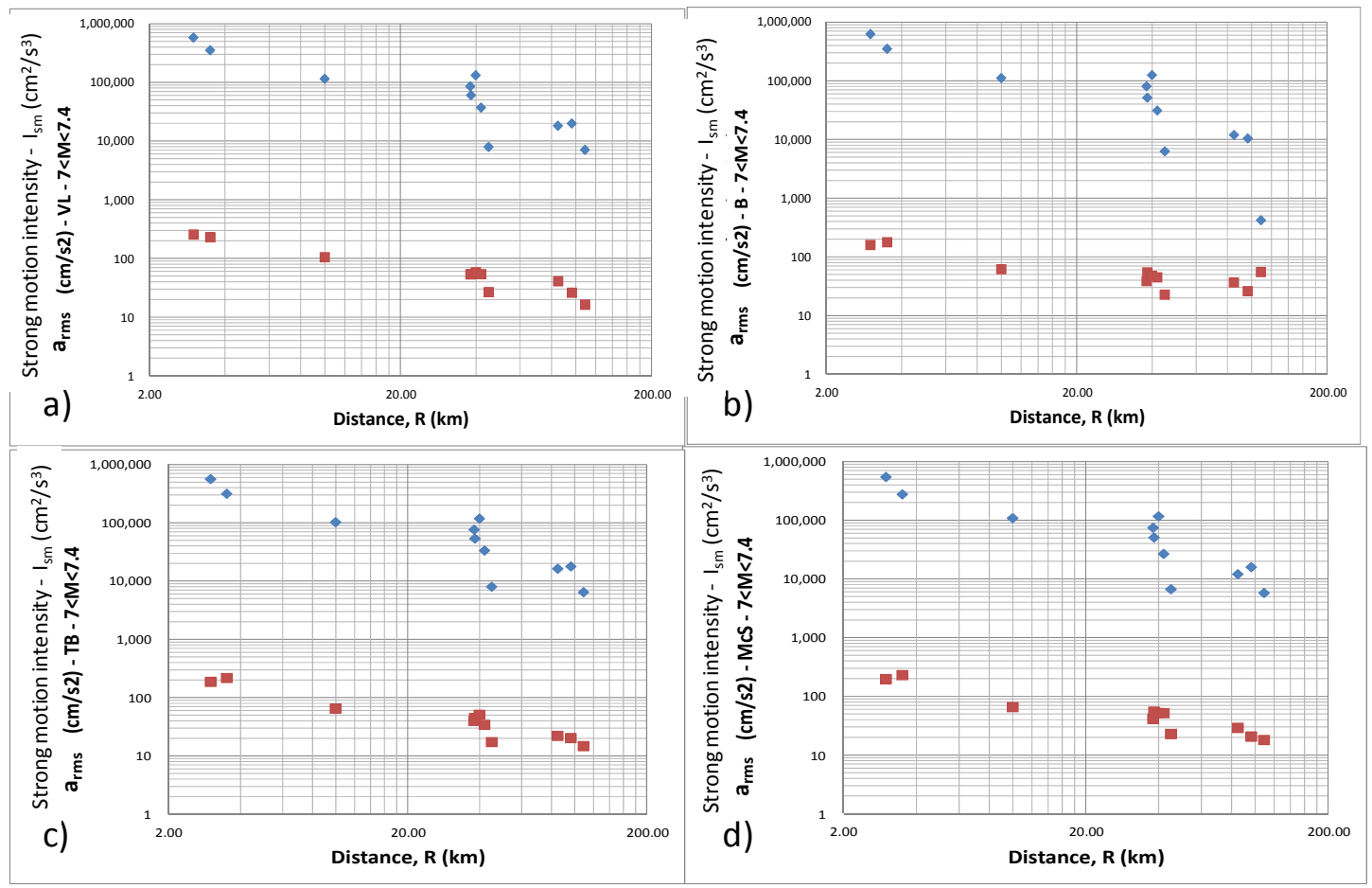

Fig. (11). Decay with distance of the motion intensity, Ism, obtained with the four definitions of duration for $7<\mathrm{M}<7.7$. Include also the variation of $a_{r m s}$ with distance for the same magnitude range, a) $\left.\left.\mathrm{VL}, \mathbf{b}\right) \mathrm{B}, \mathbf{c}\right) \mathrm{TB}$ and d) $\mathrm{McS}$.
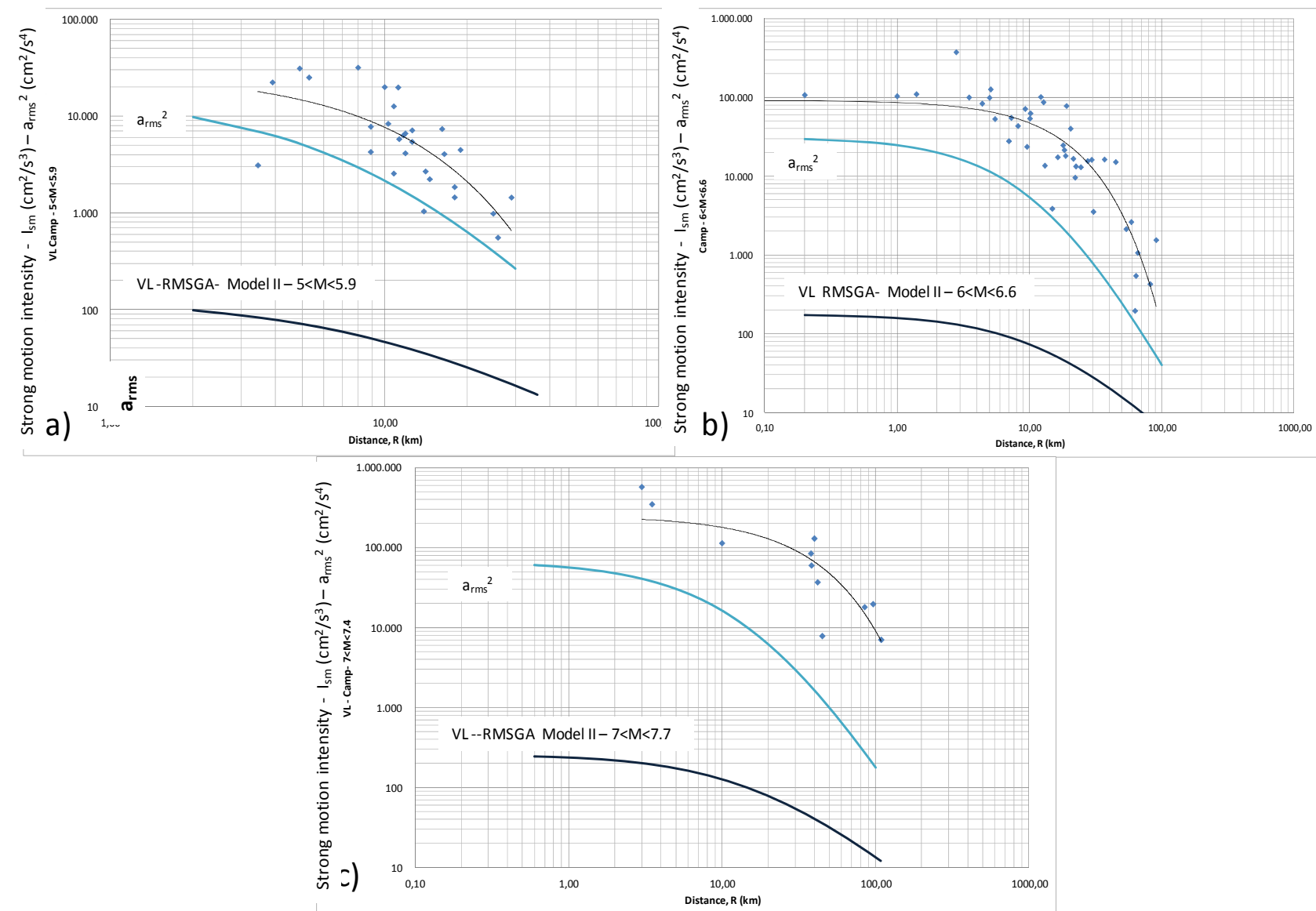

Fig. (12). Variation with distance of motion intensity, $I s m$, and the square of $a_{r m s}$ from VL definition and three magnitude ranges, a) $5<\mathrm{M}<5.9$; b) $6<\mathrm{M}<6.6$ and $(\mathbf{c}) 7<\mathrm{M}<7.7$. 


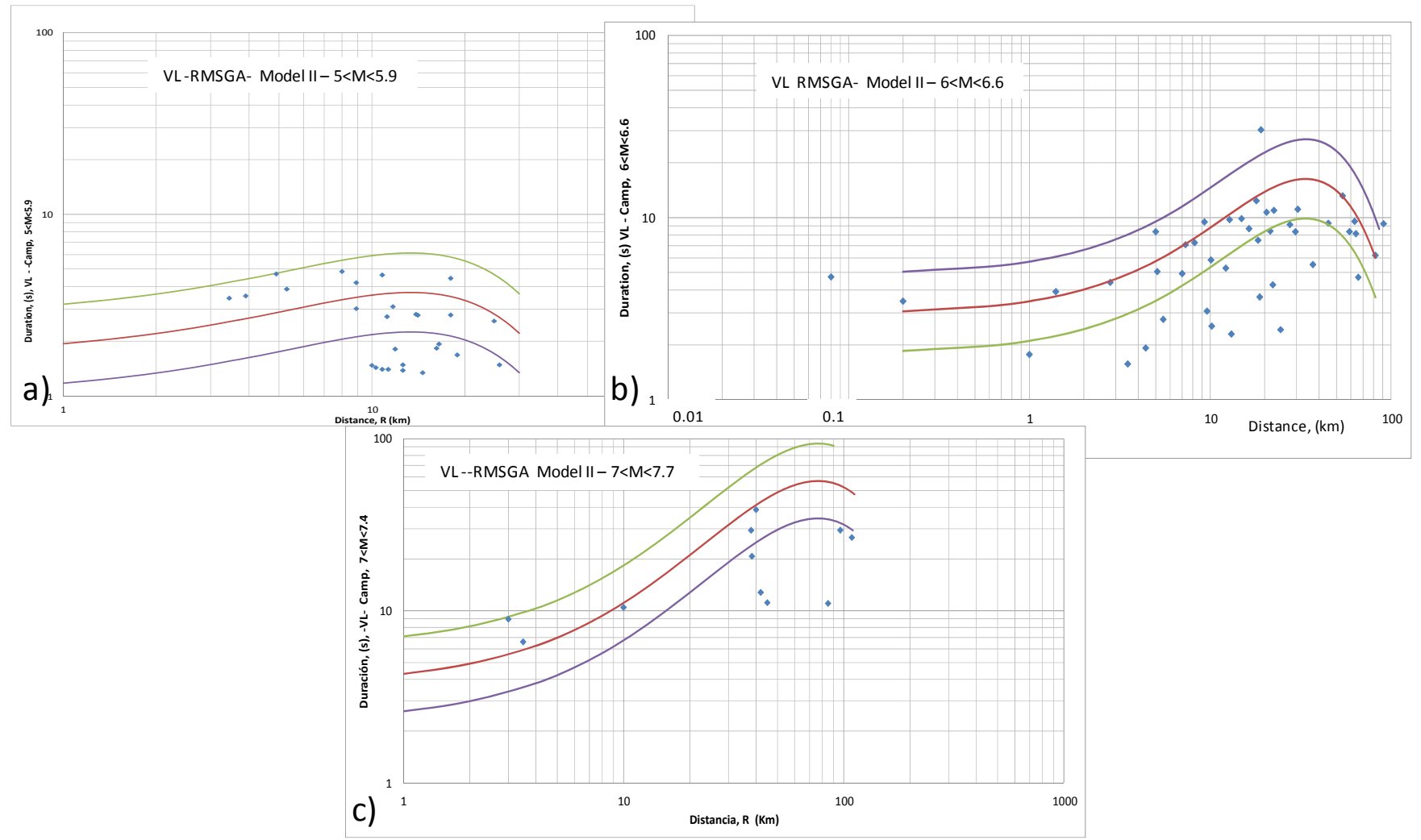

Fig. (13). Inferred variation with distance of the duration in seconds of the strong section of an accelerogram for VL definition and three magnitude ranges, a) $5<\mathrm{M}<5.9$; b) $6<\mathrm{M}<6.6$ and c) $7<\mathrm{M}<7.7$.

One can infer from Fig. (12) after comparing the $a_{r m s}$ square and the mean of the Ism, that the previously mentioned tendency for the change with distance of the duration in time, $\mathrm{D}(\mathrm{s})$ of the strong section of the accelerogram holds and it increases with distance up to a certain point after which it starts to reduce. This is shown in Fig. (13) where the ratio of the motion intensity divided by the squared of the $a_{r m s}$ is presented with distance, along with the durations estimated for the different earthquakes included in the data base.

An interval that may approximate one standard deviation of the prediction is also included in Fig. (13). Note that the durations appear to be somewhat lower than the predictions and that the tendency is not very clear. However, the rationale of the analysis indicates that there should be a behavior like the one pointed out herein and further investigation is worthwhile.

\section{CONCLUSIONS AND RECOMMENDATIONS}

For all practical purposes and despite minor variations, strong motion intensity calculated from eq. 5 as the product of duration in seconds and $a_{r m s}^{2}$ both obtained with the four definitions of duration given by Vanmarcke-Lai (VL), Bolt (B), Trifunac-Brady (TB) and Mc Caan-Shah (McS) can be considered as similar or equivalent. This is a very interesting finding because the four definitions use different conceptual basis, even though only two of them (VL and TB) use explicitly the Arias intensity. Definition by McS uses the de- cline in root mean square of the ground acceleration which is not necessarily related to intensity, and Bolt definition of duration does not consider the root mean square of the ground acceleration at all. However, all of the definitions involve the $P G A$ and the accelerations above and below it, which in turn yield this interesting result.

Durations in seconds of the strong section of the accelerogram and $a_{r m s}$ values are quite different for the four definitions. It means that even though the definitions yield the same value of the energy for the strong section of the accelerogram, the duration in seconds as well as the $a_{r m s}$ may vary significantly from one definition to the other. However, such variations tend to compensate in such a way that when one of the variables is reduced, the other is increased and the final strong motion intensity tends to yield the same value.

TB durations in seconds are about double than those from VL. McS durations in seconds seem to be in agreement with VL for low $a_{r m s}$ values, for large $a_{r m s}$ values they have significant scatter. TB durations tend to be larger than those from $\mathrm{McS}$.

The ratio between strong motion intensity (Ism) and $P G A^{2}$ for the strong part of the accelerograms should be linearly proportional to duration in seconds, $\mathrm{D}(\mathrm{s})$. Plots of this ratio vs $\mathrm{D}(\mathrm{s})$ for the four definitions of duration indicate that such linear proportionality holds well only for values of durations lower than about 20 to 30 seconds for the four definitions. This should be further investigated because according to $\mathrm{VL}$ definition of duration it may hold with no exceptions. 
The Q-ratio between $P G A$ and $a_{r m s}$ should be a constant and equal to 2.74 for the duration, $T s m$, of the strong section of the accelerogram as defined in VL definition of duration. However the histograms of the Q-ratio for the four definitions of duration indicate that this ratio is not nearly constant and for the VL definition has a mean value equal to 3.54 , at least for the data base used herein. The other definitions of duration yield the following mean values: TB mean Q-ratio of 5.49, B mean Q-ratio of 4.91 and $\mathrm{McS}$ mean Q-ratio of 4.16. This is not in agreement with the assumptions of VL, as mentioned above, and further research is worth. Nevertheless, the VL definition has the narrower range of the four definitions used, as well as the smaller standard deviation. Thus, it could be inferred that VL definition is more consistent in selecting shorter strong sections of the accelerogram around the PGA, even though the Q-ratio is somewhat larger than originally assumed. This is also in agreement with the fact that durations in seconds for the other definitions tend to be larger than those with the VL definition. This also implies that the VL definition tend to yield larger values of the accelerations that might cause damage to structures and liquefaction as discussed above.

Duration in seconds, $\mathrm{D}(\mathrm{s})$, of the strong section of the accelerogram does not show a clear tendency with distance for the four definitions of duration. However, given that the strong motion intensity, Ism, can be estimated by the product of the $a_{r m s}$ squared times the duration in seconds, it was used to infer the variation with distance of duration by looking into the variation of both, the $I s m$, and $a_{r m s}$ squared with distance. Resulting inferred tendency for the change with distance of the duration in time, $\mathrm{D}(\mathrm{s})$ of the strong section of the accelerogram appears to increase with distance up to a certain point after which it starts to reduce. This aspect is worth investigating.

Strong motion intensity, Ism, needs further research as it turns out to be quite similar for different definitions of the strong section even though some of the definitions do not use the energy concept in the way they treat the problem. $\mathrm{D}(\mathrm{s})$ and $a_{r m s}$ change from one definition to another, however they appear to compensate to yield the same value of the energy or motion intensity. This should be further investigated.

The $a_{r m s}$ values from, B, appear to have the largest dispersion of all definitions, see Fig. (1). It may be due to the threshold value used $(0.05 \mathrm{~g})$ in this study. However, if dif- ferent criteria were used to select the initiating damage and the end damage, it might be possible to obtain better results with this definition of strong section of an accelerogram. Note that with this it is implied to use one value for the initiation and a different one for the end. This should be further investigated.

Even though the VL definition uses a Q-ratio equal to 2.74 to define the strong section of an accelerogram, the outcome with the data used herein shows that this ratio is not nearly constant and has a mean value equal to 3.54 , at least for the data base used herein. It is not in agreement with the assumptions of $\mathrm{VL}$, as mentioned above, and further research will help to better understand this fact.

\section{CONFLICT OF INTEREST}

No funding was received by the author to conduct the discussion presented herein. However, funding was received from the National Science Foundation to complete the probabilistic assessment of liquefaction for downtown San Francisco.

\section{ACKNOWLEDGEMENTS}

Declared none.

\section{REFERENCES}

[1] E. H. Vanmarcke, and S. P. Lai, "Strong motion duration and RMS amplitude of earthquake records", Bull. Seism. Soc. Am., vol. 70, no. 4, pp. 1293-1307, 1980.

[2] M. B. Trifunac, and G. Brady, "A study on the duration of strong earthquake ground motion” Bull. Seism. Soc. Am. vol. 5, no. 3, pp. 581-626, 1975.

[3] M. Mc Cann, RMS Acceleration and Duration of Strong Ground Motion, The John A. Blume Earthquake Engineering Center, Report No. 46, Stanford University, 1980.

[4] B. A. Bolt, "Duration of strong ground motion" In: Proceedings of the $5^{\text {th }}$ World Conference on Earthquake Engineering, vol. 1, Rome, 1973.

[5] H. Echezuría, "Determination of liquefaction Opportunity for downtown San Francisco, Ca”, Engineer Thesis, Stanford University, June 1983.

[6] E. Kavazanjian, R. Roth, and H. Echezuría, "Probabilistic Evaluation of Earthquake Liquefaction Potential for Downtown San Francisco" The John A. Blume Earthquake Engineering Center, Report No 60, Stanford University, April, 1983.

[7] A. Arias, A Measure of Earthquake Intensity, Seismic Design of Nuclear Power Plants, Hansen, R., edit. MIT Press, Cambridge, 1970.

Received: October 12, 2014

Revised: November 05, 2014

Accepted: December 01, 2014

(C) Heriberto Echezuría; Licensee Bentham Open

This is an open access article licensed under the terms of the Creative Commons Attribution Non-Commercial License (http://creativecommons.org/licenses/ by-nc/3.0/) which permits unrestricted, non-commercial use, distribution and reproduction in any medium, provided the work is properly cited. 


\section{APPENDIX 1}

Table A-1. Earthquakes used in this study.

\begin{tabular}{|c|c|c|c|c|c|c|c|c|c|c|c|c|}
\hline & Earthquake & Magnitude & Distance & & Duration & (secon & & PGA & RMSA-VL & RMSA-B & RMSA-TB & RMSA-McS \\
\hline & Name \& date & Moment & $(\mathrm{km})$ & V-L & $\mathrm{B}$ & $T-B$ & MC-S & $(\mathrm{cm} / \mathrm{s} 2)$ & $(\mathrm{cm} / \mathrm{s} 2)$ & $(\mathrm{cm} / \mathrm{s} 2)$ & $(\mathrm{cm} / \mathrm{s} 2)$ & $(\mathrm{cm} / \mathrm{s} 2)$ \\
\hline 1 & Tabas (Iran) - 78 & 7,7 & 3,00 & 8,93 & 24,48 & 16,06 & 14,10 & 786,16 & 253,53 & 159,38 & 186,87 & 196,07 \\
\hline 2 & San Fernando - 71 & 6,6 & 20,50 & 10,69 & 9,26 & 13,20 & 5,80 & 212,12 & 61,28 & 62,55 & 52,45 & 74,13 \\
\hline 3 & San Fernando - 71 & 6,6 & 54,00 & 13,16 & 0,00 & 55,16 & 61,40 & 42,4 & 12,72 & 0,00 & 5,89 & 5,80 \\
\hline 4 & San Fernando - 71 & 6,6 & 82,00 & 6,20 & 0,00 & 18,36 & 1,40 & 37,37 & 8,28 & 0,00 & 4,71 & 10,54 \\
\hline 5 & San Fernando - 71 & 6,6 & 59,00 & 8,36 & 0,20 & 12,98 & 5,60 & 76,93 & 17,67 & 76,63 & 13,45 & 16,94 \\
\hline 6 & San Fernando - 71 & 6,6 & 66,00 & 4,70 & 0,00 & 9,30 & 0,80 & 55,94 & 15,02 & 0,00 & 10,19 & 22,51 \\
\hline 7 & San Fernando - 71 & 6,6 & 29,60 & 8,35 & 5,80 & 15,68 & 3,20 & 147,18 & 43,92 & 36,40 & 30,46 & 54,62 \\
\hline 8 & San Fernando - 71 & 6,6 & 27,60 & 9,13 & 9,87 & 18,42 & 13,00 & 147,22 & 41,24 & 35,79 & 31,97 & 38,86 \\
\hline 9 & San Fernando - 71 & 6,6 & 22,50 & 10,94 & 8,14 & 12,76 & 11,60 & 111,89 & 34,85 & 36,73 & 30,74 & 32,44 \\
\hline 10 & San Fernando - 71 & 6,6 & 18,40 & 7,50 & 6,72 & 7,42 & 4,60 & 200,22 & 53,49 & 54,17 & 51,01 & 59,53 \\
\hline 11 & San Fernando - 71 & 6,6 & 64,00 & 8,15 & 0,00 & 8,74 & 5,20 & 27,48 & 8,15 & 8,15 & 6,56 & 7,61 \\
\hline 12 & San Fernando - 71 & 6,6 & 91,00 & 9,24 & 0,00 & 7,94 & 6,60 & 38,28 & 12,91 & 0,00 & 13,21 & 13,67 \\
\hline 13 & Borrego Mount - 68 & 6,6 & 45,00 & 9,31 & 9,96 & 49,24 & 26,60 & 139,37 & 40,29 & 66,90 & 26,63 & 21,99 \\
\hline 14 & Daily City - 57 & 5,2 & 3,45 & 3,45 & 0,38 & 3,22 & 1,20 & 124,65 & 30,05 & 48,24 & 29,70 & 37,89 \\
\hline 15 & Imperial Valley - 40 & 7 & 10,00 & 10,47 & 29,30 & 24,40 & 25,20 & 352,34 & 104,25 & 61,45 & 64,75 & 65,57 \\
\hline 16 & Lyttle Creek - 70 & 5,3 & 18,00 & 4,44 & 1,10 & 5,48 & 0,20 & 84,41 & 20,44 & 35,19 & 17,69 & 34,72 \\
\hline 17 & Lyttle Creek - 70 & 5,3 & 18,00 & 2,79 & 0,04 & 2,78 & 0,60 & 75,29 & 22,82 & 75,29 & 21,37 & 25,24 \\
\hline 18 & Lyttle Creek - 70 & 5,3 & 29,00 & 9,76 & 0,00 & 10,60 & 2,00 & 44,17 & 12,18 & 0,00 & 11,30 & 17,29 \\
\hline 19 & Parkfield - 66 & 6,1 & 63,00 & 9,52 & 0,00 & 18,98 & 10,20 & 17,67 & 4,52 & 0,00 & 3,04 & 3,83 \\
\hline 20 & Parkfield - 66 & 6,1 & 5,50 & 2,76 & 7,30 & 6,72 & 2,20 & 458,34 & 138,60 & 82,85 & 84,34 & 108,33 \\
\hline 21 & Parkfield - 66 & 6,1 & 9,60 & 3,06 & 7,62 & 10,86 & 4,00 & 273,83 & 87,79 & 52,11 & 44,25 & 63,82 \\
\hline 22 & Parkfield - 66 & 6,1 & 14,90 & 9,86 & 0,56 & 28,06 & 70,67 & 70,67 & 19,77 & 29,32 & 11,14 & 11,27 \\
\hline 23 & Parkfield - 66 & 6,1 & 0,08 & 4,72 & 12,08 & 6,96 & 2,00 & 716,46 & 154,51 & 95,62 & 121,00 & 200,06 \\
\hline 24 & Kern County - 52 & 7,4 & 109,00 & 26,64 & 0,14 & 29,72 & 17,80 & 55 & 16,26 & 54,74 & 14,70 & 17,97 \\
\hline 25 & Kern County - 52 & 7,4 & 42,00 & 12,78 & 15,56 & 28,84 & 10,20 & 193,35 & 53,73 & 44,66 & 33,96 & 51,07 \\
\hline 26 & Kern County - 52 & 7,4 & 85,00 & 11,03 & 9,00 & 33,70 & 14,40 & 132,5 & 40,43 & 36,37 & 21,96 & 28,87 \\
\hline 27 & Coyote Lake - 79 & 5,8 & 8,90 & 4,20 & 1,59 & 5,97 & 3,40 & 127,59 & 43,11 & 46,39 & 27,15 & 33,79 \\
\hline 28 & Coyote Lake - 79 & 5,8 & 8,00 & 4,84 & 5,23 & 4,08 & 1,10 & 355,18 & 81,22 & 75,52 & 84,11 & 146,51 \\
\hline 29 & Coyote Lake - 79 & 5,8 & 5,30 & 3,87 & 5,24 & 8,35 & 1,00 & 264,99 & 80,71 & 63,58 & 52,22 & 118,80 \\
\hline 30 & Coyote Lake - 79 & 5,8 & 4,90 & 4,69 & 7,12 & 8,20 & 6,30 & 255,18 & 81,61 & 70,60 & 65,51 & 73,24 \\
\hline 31 & Coyote Lake - 79 & 5,8 & 3,90 & 3,55 & 3,86 & 5,48 & 0,60 & 225,73 & 79,51 & 73,17 & 60,72 & 135,19 \\
\hline 32 & Imperial Valley - 79 & 6,5 & 0,20 & 3,47 & 10,36 & 4,78 & 3,60 & 510,36 & 175,80 & 100,46 & 142,11 & 160,50 \\
\hline 33 & Imperial Valley - 79 & 6,5 & 1,40 & 3,92 & 10,53 & 8,17 & 5,20 & 706,65 & 167,38 & 100,07 & 110,00 & 127,10 \\
\hline 34 & Imperial Valley - 79 & 6,5 & 2,80 & 4,40 & 18,87 & 9,76 & 10,10 & 794,98 & 291,63 & 140,20 & 185,85 & 187,10 \\
\hline 35 & Imperial Valley - 79 & 6,5 & 3,50 & 1,57 & 9,61 & 5,83 & 4,10 & 628,13 & 251,89 & 97,25 & 120,00 & 144,00 \\
\hline 36 & Imperial Valley - 79 & 6,5 & 1,00 & 1,77 & 15,44 & 8,26 & 4,80 & 549,62 & 241,54 & 81,51 & 106,30 & 132,50 \\
\hline 37 & Imperial Valley - 79 & 6 & 4,40 & 1,92 & 11,14 & 6,64 & 5,10 & 598,96 & 208,20 & 84,92 & 106,20 & 119,60 \\
\hline 38 & Imperial Valley - 79 & 6,5 & 12,20 & 5,27 & 11,57 & 9,00 & 5,30 & 372,95 & 138,47 & 101,70 & 111,59 & 140,10 \\
\hline 39 & Imperial Valley - 79 & 6,5 & 9,30 & 9,46 & 12,59 & 11,69 & 5,40 & 264,99 & 86,87 & 73,28 & 74,20 & 103,00 \\
\hline 40 & Imperial Valley - 79 & 6,5 & 10,20 & 2,53 & 12,16 & 8,91 & 5,00 & 422,03 & 157,40 & 79,21 & 89,83 & 111,80 \\
\hline 41 & Imperial Valley - 79 & 65 & 18,00 & 12,34 & 17,94 & 19,83 & 18,00 & 147,22 & 44,65 & 35,12 & 33,42 & 35,12 \\
\hline 42 & Imperial Valley - 79 & 6,5 & 21,50 & 8,42 & 8,82 & 21,50 & 15,50 & 147,22 & 44,44 & 37,72 & 26,66 & 30,62 \\
\hline 43 & Imperial Valley - 79 & 6,5 & 16,40 & 8,68 & 10,44 & 15,14 & 5,30 & 147,22 & 44,71 & 38,14 & 32,17 & 47,19 \\
\hline 44 & Imperial Valley - 79 & 6,5 & 7,00 & 4,92 & 11,55 & 14,41 & 11,20 & 215,92 & 75,10 & 46,84 & 41,61 & 44,86 \\
\hline 45 & Imperial Valley - 79 & 6,5 & 7,30 & 7,09 & 12,39 & 11,89 & 6,80 & 255,18 & 87,95 & 64,56 & 64,43 & 81,95 \\
\hline 46 & Imperial Valley - 79 & 6,5 & 10,10 & 5,84 & 12,98 & 11,25 & 7,30 & 274,81 & 95,94 & 62,69 & 65,59 & 76,45 \\
\hline 47 & Imperial Valley - 79 & 6,5 & 13,10 & 2,29 & 5,28 & 17,74 & 5,28 & 196,29 & 76,98 & 41,76 & 26,26 & 36,77 \\
\hline 48 & Imperial Valley - 79 & 6,5 & 22,20 & 4,27 & 1,91 & 26,60 & 29,30 & 127,59 & 47,37 & 44,73 & 17,98 & 17,86 \\
\hline 49 & Imperial Valley - 79 & 6,5 & 24,50 & 2,42 & 4,59 & 11,90 & 4,90 & 206,11 & 73,30 & 48,64 & 20,01 & 47,08 \\
\hline 50 & Imperial Valley - 79 & 6,5 & 30,50 & 11,09 & 2,18 & 11,34 & 10,30 & 68,7 & 17,82 & 22,98 & 16,72 & 17,34 \\
\hline 51 & Imperial Valley - 79 & 6,5 & 5,10 & 5,05 & 12,48 & 6,39 & 4,50 & 500,54 & 158,24 & 99,51 & 133,56 & 153,20 \\
\hline 52 & Imperial Valley - 79 & 6,5 & 8,20 & 7,27 & 10,21 & 12,03 & 5,10 & 225,73 & 77,19 & 62,23 & 56,92 & 79,83 \\
\hline 53 & Imperial Valley - 79 & 6,5 & 19,10 & 30,29 & 32,79 & 29,77 & 31,10 & 116,85 & 50,70 & 47,36 & 48,53 & 48,22 \\
\hline 54 & Imperial Valley - 79 & 6,5 & 12,80 & 9,73 & 21,98 & 21,52 & 21,20 & 264,99 & 94,48 & 60,82 & 60,36 & 62,85 \\
\hline 55 & Imperial Valley - 79 & 6,5 & 18,80 & 3,66 & 13,67 & 26,40 & 19,40 & 186,48 & 70,29 & 2,00 & 24,91 & 28,47 \\
\hline 56 & Imperial Valley - 79 & 6,5 & 37,00 & 5,51 & 8,53 & 27,16 & 8,70 & 157,03 & 54,31 & 37,75 & 50,04 & 37,32 \\
\hline
\end{tabular}


Table A-1. Contd.......

\begin{tabular}{|c|c|c|c|c|c|c|c|c|c|c|c|c|}
\hline & Earthquake & Magnitud & Distance & L & uration & (secon & & PGA & RMSA-VL & RMSA-B & RMSA-TB & RMSA-McS \\
\hline & Name \& date & Moment & $(\mathrm{km})$ & $\mathrm{V}-\mathrm{L}$ & $\mathrm{B}$ & T-B & MC-S & $(\mathrm{cm} / \mathrm{s} 2)$ & $(\mathrm{cm} / \mathrm{s} 2)$ & $(\mathrm{cm} / \mathrm{s} 2)$ & $(\mathrm{cm} / \mathrm{s} 2)$ & $(\mathrm{cm} / \mathrm{s} 2)$ \\
\hline 57 & Imp Val- Aftershok & 795 & 25,90 & 1,48 & 0,13 & 3,31 & 3,90 & 55,94 & 19,41 & 45,67 & 12,16 & 10,84 \\
\hline 58 & Imp Val- Aftershok & 795 & 14,10 & 2,78 & 0,44 & 10,15 & 5,55 & 95,2 & 31,14 & 62,06 & & \\
\hline 59 & Imp Val- Aftershok & 795 & 18,90 & 1,68 & 0,89 & 5,61 & 0,30 & 151,14 & 51,75 & 64,42 & 85 & 49 \\
\hline 60 & Imp Val- Aftershok & 795 & 16,50 & 1,93 & 0,43 & 5,13 & 0,35 & 144,27 & 45,95 & 87,25 & 26,73 & 91,54 \\
\hline 61 & Imp Val- Aftershok & 795 & 12,60 & 1,38 & 1,13 & 6,43 & 0,20 & 232,61 & 72,08 & 72,07 & 31,69 & 147,42 \\
\hline 62 & Imp Val- Aftershok & 795 & 11,90 & 0,92 & 0,85 & 6,47 & 0,25 & 280,7 & 85,12 & 77,12 & 30,77 & 120,13 \\
\hline 63 & Imp Val- Aftershok & 795 & 11,30 & 1,40 & 0,97 & 5,37 & 0,30 & 225,73 & 64,45 & 72,25 & 31,28 & 90,14 \\
\hline 64 & Imp Val- Aftershok & 795 & 12,60 & 1,48 & 1,04 & 4,43 & 0,55 & 130,53 & 60,67 & 68,33 & & \\
\hline 65 & Imp Val- Aftershok & 795 & 13 & 2,81 & 0,02 & 5,99 & 5,95 & 510,91 & 26 & 70,91 & & 54 \\
\hline 66 & Imp Val- Aftershok & 795 & 6,20 & 1,83 & 0,92 & 3,60 & 0,50 & 188,44 & 63,57 & 83,62 & & 100,52 \\
\hline 67 & Imp Val- Aftershok & 795 & 11,70 & 3,10 & 1,63 & 7,22 & 0,40 & 144,27 & 45,29 & 53,59 & 17 & 71,75 \\
\hline 68 & Imp Val- Aftershok & 795 & 10,30 & 1,43 & 1,40 & 5,82 & 0,70 & 259,1 & 76,57 & 72,68 & 36,02 & 98,27 \\
\hline 69 & Imp Val- Aftershok & 795 & 14,60 & 1,34 & 0,02 & 10,13 & 9,75 & 126,61 & 40,87 & 69,28 & 01 & 14,53 \\
\hline 70 & Imp Val- Aftershok & 795 & 11,20 & 2,73 & 1,92 & 2,18 & 0,70 & 258,12 & 85,39 & 98,30 & & 134,87 \\
\hline 71 & Imp Val- Aftershok & 795 & 11, & 1,81 & 1,09 & 4, & & 154,09 & & 53,21 & & 85 \\
\hline 72 & Imp Val- Aftershok & 795 & 24,90 & 2,58 & 0,26 & 5,30 & 6,05 & 58,89 & 19,54 & 46,67 & & 12,56 \\
\hline 73 & Hollister - 74 & 5 & 10,80 & 1,40 & 1,08 & 2,46 & 1,20 & 137,4 & 42,80 & 44,48 & 65 & 42,03 \\
\hline 74 & Hollister - 74 & 5 & 10,80 & 4,63 & 2,00 & 9,18 & 1,00 & 166,85 & 52,37 & 68,84 & 46 & 83,80 \\
\hline 75 & Hollister - 74 & 5 & 8,90 & 3,02 & 1,54 & 8,06 & 1,00 & 117,77 & 37,65 & 41,21 & 21,88 & 41,21 \\
\hline 76 & Sitka Alaska - 72 & 7,7 & 45,00 & 11,15 & 12,26 & 26,94 & 12,80 & 107,96 & 26,53 & 22,62 & 17 & 22,75 \\
\hline 77 & Managua-Nicaragua & 6,1 & 5,00 & 8,35 & 13,26 & 8,26 & 6,20 & 382,77 & 108,68 & 96,11 & 84 & 132,43 \\
\hline 78 & Gazly (US & 7 & & 6,59 & 11,14 & 6,73 & 5,26 & 794,94 & 00 & 176,91 & 09 & 228,27 \\
\hline 79 & St. Elias (Alka) - 79 & 7,6 & 38,30 & 20,74 & 17,58 & 26,90 & 17,10 & 157,03 & 53,72 & 54,04 & 49 & 54,36 \\
\hline 80 & St. Elias (Alka) - 79 & 7,6 & 96,60 & 29,43 & 15,49 & 43,69 & 37,69 & 88,33 & 25,86 & 25,91 & 20,13 & 20,52 \\
\hline 81 & Lima - Peru - 76 & 7,6 & 38,00 & 29,39 & 53,72 & 47,80 & 43,40 & 255,55 & 53,65 & 38,64 & 39,91 & 41,31 \\
\hline 82 & Lima - Peru - 76 & 7,6 & 40,00 & 38,67 & 55,44 & 45,60 & 43,20 & 245,36 & 58,05 & 47,51 & 50,79 & 51,75 \\
\hline 83 & Sta. Barbara - 41 & 5,9 & 10,00 & 1,47 & 3,24 & 4,46 & 0,40 & 235,55 & 116,82 & 75,98 & 64,08 & 111,91 \\
\hline
\end{tabular}

